\title{
How many Canadian kids suffer harm linked to vaping and cannabis?
}

- Cite as: CMAJ 2020 August 31;192:E1024-5. doi: 10.1503/cmaj.1095892

Posted on cmajnews.com on August 14, 2020

anadian pediatricians saw dozens of children and teens harmed by vaping and recreational cannabis last year - numbers some experts say may underestimate the problem. Yet, when it comes to vaping, many pediatricians remain unsure of how to raise the issue with young patients.

Pediatricians reported 88 cases of illness or injury related to vaping over a 12-month period, according to a one-time survey conducted as part of the Canadian Paediatric Surveillance Program. Twenty-two cases required hospitalization and 13 of those hospitalized needed intensive care.

The cases captured by the survey probably represent "the tip of the iceberg, in the sense that not all kids will consult with a pediatrician," said principal investigator Dr. Nicholas Chadi, an adolescent and addiction medicine specialist in Montreal. For example, the survey may not capture young people who visited emergency departments because "many emergency doctors are not pediatricians."

"We also did not have a $100 \%$ response rate even amongst pediatricians," Chadi said. Among 2693 pediatricians asked to participate in the survey only 1131 (42\%) responded. As such, there may be "many more" unreported cases of illness and injury related to vaping.

Chadi called the findings an "important call to action" for families and health professionals. However, nearly a third of pediatricians surveyed reported feeling somewhat or very uncomfortable discussing vaping-related health risks with patients and their families.

Chadi, who completed his pediatric residency four years ago, noted the absence of training on counselling youths about vaping. "Even today, there are no reported in the survey. In 71 cases where patient outcomes were known, nearly a third of young people suffered ongoing health issues, although the survey didn't cover what those issues comprised.

Also concerning are emerging data on vaping and the risk of coronavirus disease

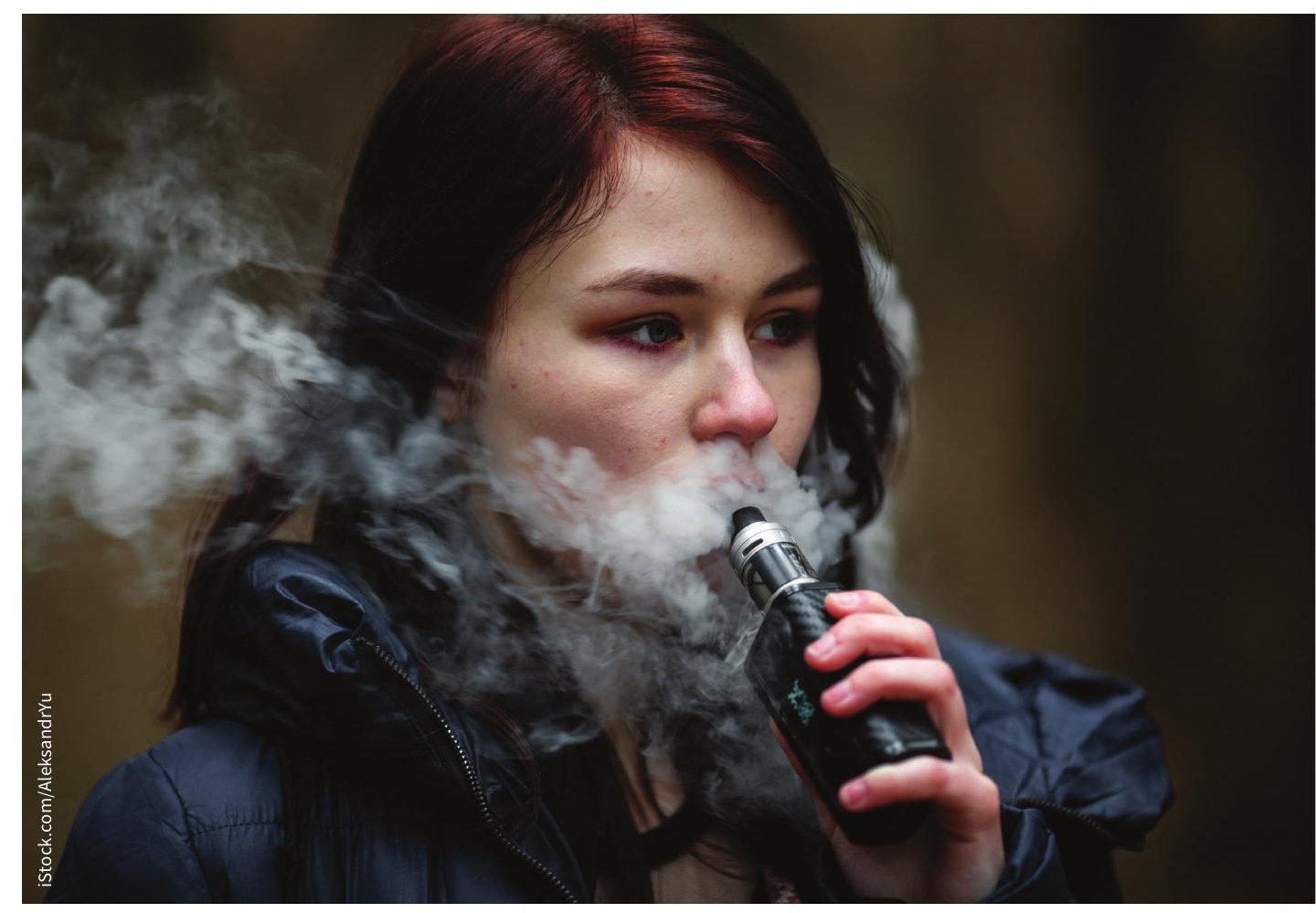

New data show that some young people experience lingering vaping-related health issues. validated screening tools to ask kids about vaping. I think a large portion of Canadian pediatricians do not know which questions to ask, what to look for, or how to prevent engagement in this behaviour," he said.

Respiratory distress, lung injury and symptoms of nicotine poisoning, were among the most common harms
2019 (COVID-19). A Stanford University study released this week found that teens and young adults who use e-cigarettes were five to seven times more likely to test positive for COVID-19 than those who did not vape. "We don't know if vaping is a risk factor itself, or if it is because of coughing associated with vaping," Chadi said. 
The Canadian Paediatric Surveillance Program also looked at harm related to recreational cannabis and found 36 cases of severe and life-threatening illness or injury among young people in 2019. Thirty-four of these patients required hospitalization, six of whom needed intensive care.

A third of all cases involved children aged 12 or younger who accidentally consumed edible cannabis products like gummies or chocolates. "It is concerning and worrisome," said study co-lead, Dr. Richard Bélanger. "These children were not looking to be exposed to cannabis."

Researchers also identified eight cases of hyperemesis syndrome or severe nausea and vomiting among teens linked to regular ingestion of cannabis edibles. "Adolescents who consume [cannabis edibles] on a regular basis, even about three times a week, [can] start vomiting," Bélanger said, noting that the syndrome also occurs in adults who regularly consume the products.

According to Bélanger, the study did not capture the impact of the legalization of cannabis edibles (legal products only hit the market late last year), but future research will.

Louise Gagnon, Ottawa, Ont. 